\title{
Update on terbinafine with a focus on dermatophytoses
}

\author{
Jason G Newland ${ }^{1,3}$ \\ Susan M Abdel-Rahman ${ }^{2,3}$ \\ Divisions of Infectious Diseases' \\ and Clinical Pharmacology \\ and Medical Toxicology², Children's \\ Mercy Hospitals and Clinics, \\ Kansas City, MO, USA; \\ ${ }^{3}$ Department of Pediatrics, \\ University of Missouri-Kansas City, \\ School of Medicine, Kansas City, \\ MO, USA
}

\begin{abstract}
Since terbinafine was introduced on the world market 17 years ago, it has become the leading antifungal for the treatment of superficial fungal infections, aided by unique pharmacologic and microbiologic profiles. This article reviews mode of action, antimycotic spectrum and disposition profile of terbinafine. It examines the data, accumulated over 15 years, on the comparative efficacy of terbinafine (vs griseofulvin, itraconazole, fluconazole) in the management of the infections for which it is primarily indicated (eg, dermatophytoses) and provides a brief discussion on its use for the treatment of non-dermatophyte infections. Finally, the available data on the newest topical and systemic formulations are introduced.
\end{abstract}

Keywords: tinea, Trichophyton, Microsporum, allylamine, antifungal

\section{Introduction}

In 2008, oral terbinafine reached the 12-year mark in the United States (US) and 17 years on the world market. Since its launch, terbinafine has garnered the top slot among topical antifungals and the oral formulation is estimated to have captured nearly $80 \%$ of the greater than US $\$ 1.5$ billion worldwide onychomycosis market (although it makes up only a minority of prescriptions written for children). ${ }^{1,2}$ Terbinafine remains the only commercially available orally available allylamine and shares the topical allylamine/benzylamine market with naftifine, butenafine and amorolfine. In recent years several new formulations have been added to the portfolio of this antimycotic including a pediatric oral granule approved by the US Food and Drug Administration in September of 2007 and a single-dose, film-forming topical solution that is now available over the counter in a number non-US markets.

This article will review the accumulated data on the mycology and pharmacology of terbinafine including its mode of action, antimycotic spectrum, disposition profile and therapeutic efficacy. The primary focus will surround dermatophytoses with a brief discussion on the role, to date, of terbinafine in non-dermatophyte infections.

\section{Clinical mycology}

Discovered in 1983, terbinafine is a member of the allylamine class of antifungals. It differs from its parent compound, naftifine, by the presence of a tert-butyl acetylene substitution of the phenyl ring on the side chain of the molecule. This substitution confers an increase in oral efficacy and an additional 10 to 100 times the in vitro activity of naftifine..$^{3,4}$

Terbinafine inhibits fungal growth by disrupting sterol biosynthesis. It abrogates the formation of ergosterol by inhibiting squalene epoxidase, the catalytic enzyme responsible for converting squalene to 2,3-oxidosqualene (an ergosterol precursor). The resultant deficiency in ergosterol compromises cell wall integrity and contributes to impaired growth and/or death of the pathogen. ${ }^{5-7}$ Notably, the biosynthesis of cholesterol in higher order eukaryotes similarly relies on the activity of squalene 
epoxidase; however, terbinafine demonstrates a markedly lower binding affinity for the mammalian enzyme. In vitro, the minimum concentration of terbinafine required to inhibit $95 \%$ of squalene epoxidase activity $\left(\mathrm{IC}_{95}\right)$ is two to three orders of magnitude greater for the mammalian enzyme $(300 \mu \mathrm{M})$ than for enzymes isolated from pathogenic yeast (0.6-2.1 $\mu \mathrm{M}){ }^{7}$

While the majority of clinical terbinafine use is observed with infections caused by dermatophytes, the susceptibility of numerous organisms including pathogenic yeast, dematiaceae, thermally dimorphic fungi and hyaline hyphomycetes has been evaluated. ${ }^{8-16}$ Although the nature of the assays employed precludes direct comparison of minimum inhibitory concentrations (MICs) between studies (ie, some were performed prior to standardization of a reference method by the Clinical and Laboratory Standards Institute (CLSI), ${ }^{17}$ some universal trends are repeated throughout. Namely, terbinafine demonstrates the greatest activity against species within the Trichophyton, Microsporum, and Epidermophyton genera followed by the dematiaceae, the filamentous fungi and a few selected pathogenic yeast.

The terbinafine MICs observed against the dermatophytes are typically several orders of magnitude lower than those reported for other fungi. ${ }^{18-23}$ This heightened susceptibility is reflected by an MIC that is an order of magnitude lower than $\mathrm{IC}_{95}$ for sterol biosynthesis. ${ }^{6}$ Given that dermatophyte growth can be fully inhibited despite only partial inhibition of sterol synthesis, the activity of terbinafine is likely accounted for by other processes including the intracellular accumulation of squalene. ${ }^{3}$ In contrast, the $\mathrm{MIC}$ to $\mathrm{IC}_{95}$ ratio for several species of fermentative yeast equals or exceeds one. ${ }^{6}$ Compared with dermatophytes, these organisms have adapted to survive under anaerobic growth conditions which are characterized by low ergosterol and high squalene concentrations. ${ }^{6}$ Reasonably, it is expected that such organisms would be less susceptible to the effects of a squalene epoxidase inhibitor.

The MICs reported for terbinafine against various dermatophytes are typically comparable to or lower than those of other antifungals active against these organisms, namely the triazoles, imidazioles and griseofulvin. ${ }^{24}$ However, a direct comparison of MICs between therapeutic agents needs to be considered in the context of achievable concentrations at the site of infection. No significant differences in terbinafine susceptibilities exist between US and non-US isolates of selected Trichophyton and Microsporum species. ${ }^{25}$ Further, the putative increase in resistance to azole antifungals observed with the "heartier" arthroconidia of the dermatophytes has not been observed with terbinafine. Both arthroconidia and microconidia of selected Trichophyton species demonstrate the same susceptibility profile to terbinafine in vitro. ${ }^{26}$

In addition to diminished susceptibility, non-dermatophyte species of fungi demonstrate resistance mechanisms not observed in the dermatophytes. Under the selective pressure of terbinafine exposure, an increase in the expression of energy-dependent efflux transporters can be observed in yeast, ${ }^{27}$ however, the expression level of orthologous transporters remains unchanged in dermatophytes. ${ }^{28}$ Similarly, filamentous fungi can upregulate the expression of an enzyme that catalyzes the breakdown of terbinafine ${ }^{29}$ but this has not been reported for dermatophytes.

Overall, an extremely low rate of spontaneous mutation conferring resistance of dermatophytes to terbinafine exists in vitro. ${ }^{30}$ Nonetheless, reduced susceptibility to terbinafine has been observed in clinical dermatophyte isolates. These appear to arise from clones harboring one of two described sequence variations in the squalene epoxidase gene. ${ }^{31,32}$ As the reported mutations do not appear to impact fungal growth in the absence of terbinafine, ${ }^{33}$ they likely signal changes to the terbinafine binding domain and ultimately binding affinity of the drug for the protein. ${ }^{34}$

While spontaneous resistance is rare, increasing reports describe cross-resistance developing between other antifungals and terbinafine. Under the selective pressure of echinocandin exposure in vitro, the upregulation of efflux transporters in yeast also reduced susceptibility to terbinafine. ${ }^{35}$ Similarly, azole "pre-exposure" in yeast can diminish susceptibility of the organisms to terbinafine. ${ }^{36-38}$ Notably, the aforementioned mechanisms of cross-resistance have not been reported for dermatophytes, in vitro or in vivo, after protracted imidazole treatment. ${ }^{36-38}$

Of potentially significant clinical relevance is the activity of terbinafine when used in combination with other antifungals for the management of invasive mycoses. Against Aspergillus fumigatus, indifference was primarily observed when terbinafine was combined with amphotericin B. Similarly, terbinafine did not improve the activity of fluconazole or itrazonazole against $A$. fumigatus; however, the triazoles demonstrated synergism when added to terbinafine. ${ }^{39}$ Against fluconazole-resistant yeast, synergy with fluconazole and itraconazole was observed in a fraction of isolates, Candida glabrata $>$ Candida tropicalis, $>$ Candida kreusi. ${ }^{40,41}$ In these pathogenic yeast antagonism has also been observed among these antifungals. ${ }^{41}$ Against ocular isolates of Fusarium, the combination of amphotericin B and terbinafine was synergistic, while the combination of terbinafine and 
triazoles demonstrated indifference. ${ }^{42}$ The ultimate utility of terbinafine in the management of invasive infections will be determined as more experience is obtained utilizing this agent as adjunct therapy.

\section{Clinical pharmacology (Tables I and 2)}

Terbinafine is efficiently absorbed following oral administration (bioavailability approx. 70\%) and this does not appear to be affected by feeding status. ${ }^{51,52}$ Over the range of clinically relevant doses (125-750 mg) terbinafine demonstrates a linear absorption profile with total body exposure increasing in direct proportion to dose. ${ }^{53}$ The rate of absorption does not appear to differ substantially between children and adults. However, the extent of absorption as reflected by maximum plasma concentrations is markedly lower in children when doses are normalized per kilogram of body weight. ${ }^{43}$

Following topical administration to normal skin, cream- and gel-based terbinafine formulations attain concentrations ranging from 746 to $949 \mathrm{ng} / \mathrm{cm}^{2}{ }^{48,54}$ Maximum stratum corneum concentrations increase by $15 \%$ with 7 days of application; however, the area under the plasma concentration vs time curve (AUC) can increase by as much as $40 \%$ over 1 week. ${ }^{54}$ Notably, concentrations obtained in the horny layer of patients with an active infection can be up to an order of magnitude lower than that observed in healthy individuals. ${ }^{55}$ While topical preparations are well absorbed into the stratum corneum, the resultant systemic exposure is several orders of magnitude lower than observed after oral terbinafine administration (Tables 1 and 2).

Terbinafine is extensively distributed with estimates of apparent distribution volume approaching $20 \mathrm{~L} / \mathrm{kg} .^{53,56}$ This relatively large volume of distribution results from the drugs high degree of lipophilicity, extensive protein binding profile and ability to concentrate in adipose and keratin rich tissue. ${ }^{56,57}$ At steady-state, concentrations observed in sebum, stratum corneum and hair exceed those observed in the plasma by as much as an order of magnitude. Although lower in the stratum corneum of hyperkeratotic tissue, terbinafine concentrations remain elevated following the discontinuation of oral therapy and persist in excess of 1 month after stopping treatment. ${ }^{58}$

At least seven cytochromes P450 (CYP) appear to be responsible for metabolizing terbinafine into more than 15 metabolites..$^{59}$ In adults, the N-demethyl and carboxybutyl metabolites constitute the largest fraction of the metabolites observed. Maximum circulating concentrations and total body exposure are comparable or in excess of those observed with the parent compound. Notably, the circulating half-life for the carboxy metabolites were twice as long as that of terbinafine. ${ }^{46}$ Although the metabolites lack an appreciable antifungal activity, they may contribute to the drug interactions and/or side effects observed following administration. ${ }^{51,60}$

Given the polyfunctional nature of terbinafine as a substrate for the CYP450, the magnitude of potential drug interactions would be predicted to be low as compared with other drugs. ${ }^{61-63}$ However, this is not the case for interactions mediated by CYP2D6. Terbinafine exhibits potent inhibition of this enzyme in vitro (apparent inhibitor rate constant $\left(\mathrm{k}_{\mathrm{i}}\right)$ approx. $30 \mathrm{nM}$ ) and correspondingly marked reduction in the metabolism of the CYP2D6 substrate dextromethorphan in vivo. ${ }^{60,64}$ Importantly, the activity of CYP2D6 may not return to normal for months after the completion of a prolonged course of therapy. ${ }^{64}$ Clinically, terbinafine is demonstrated to interact with concurrently administered CYP2D6 substrates including amitriptyline, nortriptyline, desipramine, and

Table I Pharmacokinetic parameter estimates of terbinafine following oral administration

\begin{tabular}{|c|c|c|c|c|c|c|}
\hline Parameter $^{\mathbf{a}}$ & $\begin{array}{l}\text { Adults I } 25 \mathrm{mg} \\
\text { single-dose } \\
(\mathrm{n}=26)^{43,44}\end{array}$ & $\begin{array}{l}\text { Adults } 250 \mathrm{mg} \\
\text { single-dose } \\
(\mathrm{n}=29)^{45,46}\end{array}$ & $\begin{array}{l}\text { Adults I } 25 \mathrm{mg} \\
\text { steady-state } \\
(\mathrm{n}=10)^{43}\end{array}$ & $\begin{array}{l}\text { Adults } 250 \mathrm{mg} \\
\text { steady-state } \\
(\mathrm{n}=22)^{46,47}\end{array}$ & $\begin{array}{l}\text { Children } \\
\text { I } 25 \mathrm{mg} \text { single-dose } \\
(\mathrm{n}=\mathbf{2 8})^{43,44}\end{array}$ & $\begin{array}{l}\text { Children I } 25 \mathrm{mg} \\
\text { steady-state } \\
(\mathrm{n}=16)^{43}\end{array}$ \\
\hline$T_{\max }(h)$ & $1.3-1.5$ & $1.4-1.5$ & 1.6 & 1.2 & $1.7-2.1$ & 1.8 \\
\hline $\mathrm{C}_{\max }(\mathrm{ng} / \mathrm{mL})$ & $506-565$ & $1340-1656$ & 646 & $1700^{\mathrm{b}}$ & 706-909 & 1059 \\
\hline AUC (h*ng/mL) & $1624-2135$ & $4740-6762$ & 3720 & $1048 \mid$ & $2967-4104$ & $585 I$ \\
\hline $\mathrm{Cl} / \mathrm{F}(\mathrm{L} / \mathrm{h} / \mathrm{kg})$ & 1.2 & & 0.55 & 0.4 & 1.9 & 1.7 \\
\hline Vss/F (L/kg) & 19.2 & & & & 19.5 & \\
\hline $\mathrm{t}_{1 / 2 \alpha}(\mathrm{h})$ & 0.7 & 0.35 & & & 1.2 & \\
\hline $\mathrm{t}_{1 / 2 \beta}(\mathrm{h})$ & 26.7 & $12.6-14.2$ & & & 14.7 & \\
\hline $\mathrm{t}_{\mathrm{I} / 2 \gamma}(\mathrm{h})$ & & & & 396 & 156 & \\
\hline
\end{tabular}

Notes: avalues represent the mean reported values from the referenced studies (when more than one study is referenced, values represent the range of reported mean

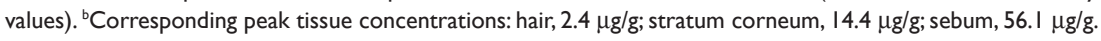

Abbreviations: $\mathrm{T}_{\max }$, time at maximum plasma concentration; $\mathrm{C}_{\max }$, maximum plasma concentration; $\mathrm{AUC}$, area under the plasma concentration vs time curve; $\mathrm{Cl} / \mathrm{F}$, apparent oral clearance; $V_{s s} / F$, steady-state volume of distribution; $\mathrm{t}_{1 / 2 \alpha^{\prime}}$, alpha-phase half-life; $\mathrm{t}_{1 / 2 \beta}$, beta-phase half-life, $\mathrm{t}_{1 / 2 \gamma^{\prime}}$, gamma-phase or terminal half-life. 
Table 2 Local and systemic estimates of exposure following topical terbinafine application

\begin{tabular}{|c|c|c|c|}
\hline Parameter $^{a}$ & $\begin{array}{l}\text { I\% gel } \times 7 \text { days } \\
\text { healthy } \operatorname{skin}^{48,49}\end{array}$ & $\begin{array}{l}\text { I\% cream } \\
7 \text { days }^{48,50,54}\end{array}$ & $\begin{array}{l}\text { I\% FFS I } \\
\text { application }^{50}\end{array}$ \\
\hline Stratum corneum $C_{\max }\left(\mu g / \mathrm{cm}^{2}\right)$ & 0.91 & $0.94-2$ & 5 \\
\hline Stratum corneum AUC $\left(h^{*} \mu g / \mathrm{cm}^{2}\right)$ & 12.7 & $\mid 1.7-13.5$ & 104.2 \\
\hline Tissue $\mathrm{t}_{1 / 2}(\mathrm{~h})$ & 1.2 & 68 & 162 \\
\hline Plasma $C_{\text {max }}(\mathrm{ng} / \mathrm{mL})$ & 3.82 & & \\
\hline Plasma AUC ( $\left(h^{*} \mathrm{ng} / \mathrm{mL}\right)$ & 63 & & \\
\hline
\end{tabular}

Notes: ${ }^{a}$ Values represent the mean reported values from the referenced studies (when more than one study is referenced, values represent the range of reported mean values). Abbreviations: $\mathrm{C}_{\max }$, maximum observed concentration, $\mathrm{AUC}$, area under the concentration vs time curve; $\mathrm{t}_{1 / 2}$, half-life.

venlafaxine. ${ }^{65-68}$ Other drugs harboring the potential to interact with terbinafine include perphenazine, metoprolol, encainide and propafenone. ${ }^{69}$

For drugs that are not substrates of CYP2D6 (eg, anticoagulants, corticosteroids, oral contraceptives, tolbutamide, cyclosporine, midazolam, digoxin and terfenadine) terbinafine has only a modest or minimal affect on their metabolism. ${ }^{70-74}$ However, as a substrate of the cytochromes $\mathrm{P} 450$, the pharmacokinetics of terbinafine are altered with the concurrent administration of several agents (eg, cimetidine, terfenadine, rifampin). ${ }^{70,75}$

The clearance of terbinafine is triphasic with the terminal elimination half-life approximating 100 hours after a single dose and 22 days with durations of therapy spanning several months. ${ }^{44,76}$ Approximately $80 \%$ of terbinafine's metabolites are excreted by the kidney with the remaining fraction eliminated in the feces. ${ }^{44}$ This protracted rate of elimination accounts for the magnitude of accumulation observed with terbinafine after repeated dosing and the persistence in plasma and tissues long after discontinuation of the drug. ${ }^{47}$ While this confers a distinct advantage to the allylamine permitting shorter courses of therapy, it poses a unique disadvantage for patients experiencing drug-related adverse events.

\section{Therapeutic use}

Terbinafine is indicated for use in the management of cutaneous dermatophytoses (eg, tinea corporis, tinea cruris and tinea pedis), onychomycosis and most recently tinea capitis. In addition, terbinafine use has been explored in a number of superficial and systemic mycoses involving pathogens other than the dermatophytes. The results of openlabel and randomized trials exploring the utility of terbinafine in various infections is detailed in the following sections.

\section{Cutaneous dermatophytoses}

Dermatophyte infections of the glabrous skin, groin and feet can be caused by any of a number of dermatophyte species. ${ }^{77}$
While these infections typically respond to topical antifungals, oral therapy is often indicated when the lesions are widespread or chronic in nature. ${ }^{78}$

Terbinafine applied topically as a $1 \%$ cream, gel or solution demonstrates utility in the management of both tinea corporis and tinea cruris. ${ }^{79}$ The application of terbinafine once-daily for 7 to 14 days resulted in mycological cure rates ranging from $84 \%$ to $94 \%$, clinical cure rates ranging from $75 \%$ to $84 \%$ and overall efficacy rates ranging from $65 \%$ to $83 \%{ }^{80-86}$ The observed treatment response with topical terbinafine is significantly greater than reported for placebo wherein clinical, mycological and complete cure rates range from $8 \%$ to $22 \%{ }^{81,83}$ Topically applied terbinafine also demonstrated statistically greater mycological response rates than a 2 -week course of $2 \%$ ketoconazole cream, ${ }^{80}$ whereas clinical response rates were comparable to a $0.6 \%$ gel containing the garlic-derived, sulfuric compound ajoene. ${ }^{84}$

Following oral administration for the treatment of tinea corporis and tinea cruris, clinical and mycological cure rates observed with terbinafine have ranged from $71 \%$ to $100 \%$ and $78 \%$ to $100 \%$, respectively. ${ }^{78,87-89}$ No significant differences in mycological or clinical cure rates were observed between terbinafine and griseofulvin in these studies; ${ }^{87-89}$ however, higher relapse rates were observed with griseofulvin. ${ }^{88,89}$ Tinea imbricata, a variant of tinea corporis found predominantly in tropical countries, manifests as concentric rings of papular plaques that are chronic in nature and relatively recalcitrant to antifungal therapy. In a single randomized, controlled trial 4 weeks of treatment with terbinafine demonstrated higher overall efficacy rates (100\%) and lower relapse rates $(16 \%)$ as compared with itraconazole $(89 \%$ efficacy, $75 \%$ relapse).$^{90}$

Tinea pedis is a dermatophyte infection of the foot that generally takes one of three forms: 1) interdigital infections characterized by cracking and fissuring of the skin in the webbing between the toes, 2) acute vesicular infections which present with erythema, bullous eruptions and bacterial 
super-infections and 3) a chronic form of infection with scaling that covers the entire foot typically referred to as "dry" or "moccasin" type tinea pedis. ${ }^{91}$ The nature and extent of infection often determines whether oral therapy is required or whether symptomatic relief can be obtained with topical therapy. ${ }^{92}$

Although topical terbinafine formulations in excess of $1 \%$ have been investigated, superficial treatment of tinea pedis typically relies on 5 to 7 days of application with the $1 \%$ cream, gel or solution (as described above for infections of the skin and groin). Mycologic cure rates are comparable irrespective of formulation, ranging from $82 \%$ to $97 \%$ with overall efficacy rates of $64 \%$ to $86 \%$. Response rates are significantly greater than observed with the vehicle alone wherein mycologic cure and overall efficacy range from $22 \%$ to $37 \%$ and $4 \%$ to $26 \%$, respectively. ${ }^{83,93-96}$ Mycological cure rates, after 1 week of treatment, are also comparable to or greater than those observed after 4 weeks of treatment with topical azole preparations. ${ }^{97-99}$

Despite the advantage of a strong efficacy profile with the application of terbinafine for one week, efforts to simplify topical administration, decrease treatment duration and improve compliance has lead to the development of a polymeric film-forming solution (FFS) designed as a "one-time" dose. The acrylate/cellulose/triglyceride based formulation leaves a nearly invisible, highly-concentrated film on the skin after the carrier solvent (ethanol) has evaporated. This film remains on the site of infection nearly 6 times longer than other topical preparations and results in stratum corneum concentrations that are sustained above the MIC in excess of 2 weeks after application. ${ }^{50,100}$ FFS concentrations as high as $10 \%$ have been evaluated; however, mycological cure rates (80\%-84\%) and overall efficacy (61\%-70\%) 6 weeks after application did not appear to demonstrate dose-dependence. ${ }^{100}$ Consequently, the currently marketed formulation contains $1 \%$ terbinafine. In a study examining slightly longer-term follow-up, mycological cure rates were observed in $72 \%$ of those treated. Notably, the duration of infection prior to treatment did not appear to influence the likelihood of mycological cure. When participants were re-evaluated at 3 months, $12.5 \%$ of those individuals considered mycologically cured at 6 weeks demonstrated positive cultures, comparable to the rates observed with other topical terbinafine formulations. ${ }^{101}$

For more refractory (eg, hyperkeratotic) infections of the foot, efficacy rates comparable to those described above can be observed with topical treatment; however, this may require protracted treatment durations (ie, several months). ${ }^{55}$ In these cases, oral therapy has emerged as a reliable alternative. Orally administered terbinafine can be highly effective in the management of tinea pedis with overall efficacy rates exceeding $90 \%$ depending on the nature of infection and the regimen used. The majority of investigations have examined the efficacy of orally administered terbinafine at daily doses of $250 \mathrm{mg}$ (either divided or once daily). Efficacy rates after 6 weeks of treatment ranged from $59 \%$ to $75 \%$, increasing to $65 \%$ to $88 \% 12$ weeks after the end of therapy. ${ }^{102,103}$ This is compared with placebo and griseofulvin where efficacy rates were $0 \%$ and $27 \%$, respectively at the end of treatment and $0 \%$ and $45 \%$, respectively, 2 weeks post treatment. ${ }^{102,103} \mathrm{With}$ shorter courses of oral treatment ( $250 \mathrm{mg}$ daily $\times 2$ weeks), mycological and clinical cure rates are markedly less impressive $(23 \%-28 \%$ and $8 \%-43 \%$, respectively). However, when followed out for 6 to 16 weeks, mycological cure rates $(78 \%-86 \%)$ and clinical efficacy $(71 \%-94 \%)$ improve dramatically suggesting utility with shorter treatment durations of terbinafine. ${ }^{104,105}$ Cure rates observed with terbinafine were comparable to those observed with itraconazole (100 mg/day); however, long-term follow-up suggested that terbinafine was slightly superior to 4 weeks of itraconazole treatment and significantly superior to 2 weeks of treatment with the triazole. ${ }^{104,105}$ Data from a single study each suggest that reducing (125 $\mathrm{mg} /$ day) or increasing (500 $\mathrm{mg} /$ day) the dose of terbinafine may not substantially alter cure rates compared traditional dosing with $250 \mathrm{mg} /$ day. ${ }^{51,58}$

\section{Onychomycosis}

Approximately one-half of all nail problems are accounted for by onychomycosis, a fungal infection wherein the nails become discolored, thickened and prone to peeling or splitting. ${ }^{106}$ Dermatophytes are principally responsible for infections of the toenail, whereas over $50 \%$ of fingernail infections can be caused by non-dermatophyte species. ${ }^{107,108}$ Of the commercially available oral antifungals, griseofulvin, itraconazole and terbinafine are most commonly used for the management of onychomycosis. Efficacy rates and treatment durations vary although treatment with the latter agents typically requires shorter courses than does the former. Irrespective, the majority of studies described below document cure rates at 12 months or beyond (earlier for fingernails) to account for the protracted growth rate of nails and the extended time-frames over which drug remains in the affected nails.

Since its approval, scores of studies have evaluated numerous terbinafine dosing regimens for the treatment of onychomycosis. With the administration of daily $250 \mathrm{mg}$ 
doses, mycologic and clinical response rates observed in toenails ranged from $72 \%$ to $92 \%$ and $45 \%$ to $77 \%$, respectively. ${ }^{109-113}$ Notably, there was little difference in both clinical and mycological response rates whether patients were treated for 12,18 or 24 weeks. ${ }^{109,111-113}$ Infections of the fingernail demonstrated comparable response rates ranging from $71 \%$ to $100 \% .^{109,111,114}$ When non-dermatophyte pathogens are considered in subgroup analyses, response rates approximate $40 \%$ for infections with Candida and greater than $90 \%$ when treating Scopulariopsis brevicaulis. ${ }^{115-117}$ The combination of daily terbinafine doses $(250 \mathrm{mg})$ with chemical or mechanical removal of the nail offers little to no additional increase in efficacy over terbinafine alone. ${ }^{118,119}$ Similarly, only limited increases in efficacy are observed when daily oral therapy is combined with adjunctive therapy including once-weekly topical amorolfine or once-daily topical ciclopirox. ${ }^{120-123}$ In each study topical therapy appeared to confer slight improvements in response; however, limited sample sizes restrict their significance and superiority over terbinafine alone could not be determined.

Intermittent terbinafine dosing has also been explored for the management of onychomycosis. When the standard regimen of $250 \mathrm{mg}$ once daily was compared to intermittent dosing administered at $350 \mathrm{mg}$ daily for 2 weeks followed by 2 weeks "off" for the management of subungual onychomycosis, both mycological (56\%-58\% vs 43\%-50\%) and complete cure $(26 \%-30 \%$ vs $20 \%-24 \%)$ favored traditional dosing; however, only the latter was statistically significant. ${ }^{124}$ When compared with $500 \mathrm{mg}$ administered daily for 1 week (followed by 3 weeks off) for the treatment of distal subungual onychomycosis, traditional dosing again proved superior to intermittent dosing. Mycological cure of the target toenail (71\% vs 59\%); clinical cure of the target toenail (45\% vs 29\%); complete cure of the target toenail ( $40 \%$ vs $28 \%$ ); and complete cure of all 10 toenails (25\% vs $15 \%$ ) were all statistically greater with standard dosing. ${ }^{125}$ No significant differences in complete cure have been observed based on the number of pulses administered; however, a clear trend is noted with response rates increasing steadily from one to four pulses. ${ }^{126}$ As noted with traditional dosing, higher cure rates were observed for fingernails treated with pulsedosing as compared with toe nails. Mycological and clinical cure rates were $89 \%$ and $72 \%$ for dermatophytes, albeit lower (67\%) for infections caused by yeast. ${ }^{127}$ As expected based on the comparative data generated from traditional dosing trials, the combination of pulse therapy with ancillary topical therapy does not substantially improve outcome over treatment with terbinafine alone. ${ }^{126-128}$
In two comparative trials, terbinafine $(250 \mathrm{mg} /$ day $)$ was significantly superior to griseofulvin (500 mg/day). Mycological cure rates were significantly higher with terbinafine ( $84 \%-92 \%$ vs $45 \%-63 \%$ ), time to mycological cure significantly shorter (73 vs 93 days) and clinical cure significantly higher (76\% vs $39 \%$ ) as compared with griseofulvin. ${ }^{129,130}$ However, the exclusion of nondermatophyte pathogens in one study and the administration of sub-clinical griseofulvin doses in both studies likely resulted in an overestimate of terbinafine's superiority. In a single trial employing the recommended dose of griseofulvin (1000 mg daily) mycological response was similar between terbinafine and griseofulvin ( $88 \%$ vs $82 \%$, respectively); however, clinical response at the end of study was greater with terbinafine $(81 \%$ vs $62 \%$ ). Not surprisingly time to negative mycologic cultures was shorter for terbinafine (130 days vs 172 days). ${ }^{131}$

In three studies, traditional dose itraconazole (200 mg/day) was compared with traditional dose terbinafine ( $250 \mathrm{mg} /$ day). In only one investigation where infections were solely restricted to those caused by dermatophytes did mycological cure rates favor terbinafine ( $81 \%-92 \%$ vs $63 \%-67 \%)$. In the remaining investigations no difference in mycological cure rates were observed between the allylamine and the triazole. ${ }^{132-134}$ The remainder of studies comparing the two agents examined pulse-dosing of itraconazole. In the treatment of distal and lateral subungual onychomycosis restricted to dermatophytes, no appreciable difference was observed between itraconazole (400 mg/day one week "on" three weeks "off") and terbinafine (mycological cure rates: $75 \%-90 \%$ vs $76 \%-87 \%$, clinical cure rates $53 \%-82 \%$ vs 50\%-79\%). ${ }^{135-138}$ Not surprisingly, itraconazole demonstrated superior cure rates among the non-dermatophyte moulds (62\% vs $44 \%$ ) and Candida species ( $92 \%$ vs $40 \%) .{ }^{138}$ These studies are contradicted by a large multi-national trial wherein mycological cure rates at 18 months were significantly greater with terbinafine $(76 \%-80 \%)$ than observed with pulse-dose itraconazole $(38 \%-49 \%) .{ }^{139}$ In selected subpopulations, complete cure rates observed after 4 years remained superior in the terbinafine arm (24\%-78\%) compared with those receiving itraconazole $(24 \%-28 \%)$ as did mycological cure (46\% vs $13 \%){ }^{140,141}$

Finally, two investigations compare daily terbinafine with once weekly fluconazole (150 mg). Clinical cure rates $(21 \%-38 \%$ vs $67 \%-81 \%)$, mycological cure rates (31\%-51\% vs $75-89 \%)$ and overall efficacy (31\% vs $62 \%$ ) were inferior in fluconazole treated patients. ${ }^{135,142}$

Despite reasonable efficacy rates, the results of numerous trials indicate that a substantial fraction of onychomycosis patients treated with terbinafine remain uncured at the end 
of treatment. Consequently several investigations have attempted to address whether additional intrinsic or extrinsic factors influence treatment response. Although the majority of these investigations were not adequately powered to definitively determine an association between selected covariates and treatment failure, several trends could be observed. The studies suggested that a higher fraction of patients 1) receiving lower terbinafine doses (125 mg vs $250 \mathrm{mg}$ ), 2) with distal and lateral subungual onychomycosis, 3) with big toenail involvement, or 4) with positive mycology 3 months into treatment remain uncured at the time of follow-up. ${ }^{143-145}$ The link between other factors such as demographic characteristics, the rate of nail growth, the species of infecting pathogen, the extent and duration of disease at the time of presentation and the number of nails involved remain unclear. ${ }^{144-146}$

\section{Tinea capitis}

Ringworm of the scalp is a dermatophyte infection commonly seen among preschool and school-aged children. It is one of the few dermatophyte infections that does not adequately respond to topical therapy, often requiring 6 to 8 weeks of oral antifungal treatment. ${ }^{147}$ Griseofulvin remains the gold standard in the management of this infection, but treatment failures are common and it is not unusual for children to remain on therapy for extended durations. ${ }^{148}$

Several studies have examined the role of terbinafine in the treatment of tinea capitis; however, results need to be considered in the context of the geographic origin of the study participants given that the primary causative organisms and, thus response rates, are expected to vary between countries. ${ }^{149-151}$ The majority of these studies examine a weight-based dosing scheme with $62.5 \mathrm{mg}$ of terbinafine administered to children under $20 \mathrm{~kg}, 125 \mathrm{mg}$ administered to children between 20 and $40 \mathrm{~kg}$ and an adult dose of $250 \mathrm{mg}$ administered to children over $40 \mathrm{~kg}$.

With the administration of terbinafine for one week, Trichophyton infections are effectively treated in 56\% of children. ${ }^{152,153}$ Efficacy rates ranged from $69 \%$ to $86 \%$ after 2 weeks of treatment, averaged $65 \%$ with 4 weeks of treatment and ranged from $80 \%$ to $100 \%$ after 6 weeks of therapy. ${ }^{44,152-155}$ Corresponding mycological cure rates observed after 1, 2, 4 and 6 weeks of treatment were $60 \%$, $76 \%, 72 \%$ and $>90 \%$, respectively. ${ }^{44,152,154}$ By contrast, infections with Microsporum are less responsive to terbinafine. Response rates as low as $15 \%$ are observed with 1 to 2 weeks of therapy. ${ }^{153}$ However, extended durations of treatment and/or doubling of the dose appeared to improve the likelihood of efficacy in children harboring Microsporum and clinical and mycological response rates begin to approximate those observed for Trichophyton. ${ }^{153,156-158}$

In comparative trials, terbinafine, when used for durations of 4 weeks, appeared to be as effective as griseofulvin administered for slightly longer intervals (8 weeks). Clinical and mycological cure rates ranged from $64 \%$ to $93 \%$ and $70 \%$ to $93 \%$, respectively for terbinafine and $67 \%$ to $80 \%$ and $72 \%$ to $88 \%$, respectively for griseofulvin. ${ }^{159-161}$ As above, the exception lies with infections caused by Microsporum where griseofulvin appears to be superior to terbinafine even when the allylamine is administered for 12 weeks. ${ }^{160-162}$ Pulse regimens wherein the standard dose or double the standard dose of terbinafine is administered daily for 1 week (followed by 3 weeks off) do not appear to confer any advantage or disadvantage in the treatment of Microsporum infections over standard regimens. ${ }^{163}$ By contrast, terbinafine appeared to be slightly more effective than both itraconazole and fluconazole in treating tinea capitis. ${ }^{164}$ It should be noted that in a number of the aforementioned studies, the griseofulvin doses employed (as low as $6 \mathrm{mg} / \mathrm{kg}$ ) were markedly lower than those recommended for use in clinical practice. Consequently, the studies may have underestimated the efficacy of griseofulvin.

A single publication is available detailing the results of two randomized-controlled trials that compared 6 weeks of treatment with the recently marketed terbinafine oral granule formulation (5-8 mg/kg daily) with griseofulvin (10-20 mg/kg daily) for the management of tinea capitis. The new formulation is designed to be sprinkled on foods thereby improving the reliability with which the drug can be administered to young children ( $>4$ years of age). In these investigations, the complete cure rate observed with terbinafine was superior to griseofulvin in one trial (46\% vs $34 \%$ ) but not the other (44\% vs $43 \%$ ). Similarly mycological cure rates were significantly higher in trial 1 (62\% vs 50\%) but not in trial 2 (61\% vs 60\%). In affirmation of the results conferred in previously conducted trials, subgroup analyses in these trials revealed that terbinafine was significantly better than griseofulvin when children were infected with Trichophyton tonsurans whereas griseofulvin proved superior for the treatment of infections with Microsporum canis. ${ }^{165}$ This multi-national study also reported greater efficacy among US vs non-US infections which was likely accounted for by the higher fraction of children in the US that are infected with $T$. tonsurans.

\section{Non-dermatophyte infections}

Although not within the scope of this review, we would be remiss not to point out the increasing utilization of terbinafine, alone and in combination, for the management of 
non-dermatophyte infections. Despite its higher MIC to pathogenic yeast, topically administered terbinafine appeared effective for the management of tinea versicolor, ${ }^{166}$ and orally administered terbinafine (250 mg twice daily) has been used successfully for the treatment of cutaneous candidiasis. ${ }^{167}$ Given, however, that the majority of superficial Candida infections will respond to topical antifungals, the role of terbinafine in these infections remains unclear. A brief summary of additional non-dermatophyte infections wherein terbinafine has been utilized is provided in Table 3 .

\section{Adverse effects}

Terbinafine has been extensively used with a relatively low incidence of reported adverse drug reactions. Clinical trials evaluating the efficacy of orally administered terbinafine in both children and adults have noted adverse event rates in as high as 52\%; however, less than $10 \%$ were attributed to the drug. ${ }^{165,182-184}$ Most terbinafine related adverse events are mild or moderate and include gastrointestinal complaints (eg, nausea, abdominal pain, vomiting, diarrhea), cutaneous eruptions, weight gain, appetite changes, headaches, and vertigo. ${ }^{43,152,165,185,186}$ Those adverse reactions involving the gastrointestinal system and skin are most commonly associated with discontinuation of therapy, ${ }^{165,186}$ with the risk of discontinuation estimated at $3.4 \%$. $^{187}$

Serious adverse drug reactions, most commonly involving the liver and the hematologic system, are only rarely reported with terbinafine use $(0.04 \%) .{ }^{188}$ Hepatotoxicity ranging from mild transaminitis to fulminant liver failure has been

Table 3 Case-reports and open-label studies examining terbinafine use in non-dermatophyte infections

\begin{tabular}{|c|c|c|c|c|}
\hline Organism & Site & Dosing regimen & Outcome & Reference \\
\hline \multirow[t]{2}{*}{ Aspergillus spp. } & toenail & 500 mg/day (pulse: I wk/mos) & clinical and mycological & 168 \\
\hline & & 3 months & cure $(88 \%)$ & \\
\hline \multirow[t]{2}{*}{ Aspergillus flavus } & muscle $^{a}$ & $250 \mathrm{mg}$ daily & resolution & 169 \\
\hline & & 13 weeks & & \\
\hline \multirow[t]{2}{*}{ Aspergillus sydowii } & toenail & 500 mg/day (pulse: I wk/mos) ${ }^{b}$ & failure & 128 \\
\hline & & 3 months & & \\
\hline \multirow[t]{2}{*}{ Aspergillus ustus } & skin $^{\mathrm{a}}$ & not provided ${ }^{c}$ & resolution & 170 \\
\hline & & II months & & \\
\hline \multirow[t]{2}{*}{ Cladosporium carrionii } & skin & 500 mg daily & cure or clinical & 171,172 \\
\hline & & 4-12 months & improvement (83\%-100\%) & \\
\hline \multirow[t]{2}{*}{ Curvularia lunata } & heart valve & 125 mg twice daily ${ }^{\mathrm{d}, \mathrm{e}}$ & tissue mycologically & 173 \\
\hline & (endocarditis) & 7 years & negative & \\
\hline \multirow[t]{2}{*}{ Fonsecaea monophora } & skin & $250 \mathrm{mg}$ daily ${ }^{\mathrm{b}}$ & clinical and mycological & 174 \\
\hline & & $7-10$ weeks & cure & \\
\hline \multirow[t]{2}{*}{ Fonsecaea pedrosoi } & skin & 500 mg daily & cure or clinical & 171,172 \\
\hline & & 4-12 months & improvement (83\%-100\%) & \\
\hline \multirow[t]{2}{*}{ Paecilomyces lilacinus } & cornea (keratitis) & $250 \mathrm{mg}$ once daily $\mathrm{b}, \mathrm{c}$ & resolution & 175,176 \\
\hline & & $10-12$ weeks & & \\
\hline \multirow[t]{2}{*}{ Paracoccidoides brasiliensis } & perineum/scrotum & $250 \mathrm{mg}$ twice daily & resolution & 177 \\
\hline & & 6 months & & \\
\hline \multirow[t]{2}{*}{ Piedra hortae } & scalp & $250 \mathrm{mg}$ once daily & effective & 178 \\
\hline & & 6 weeks & & \\
\hline \multirow[t]{2}{*}{ Phialphora parasitica } & disseminated $^{\mathrm{a}}$ & 125 mg twice daily & drug discontinued & 179 \\
\hline & & 2 months & & \\
\hline \multirow[t]{2}{*}{ Sporothix schenckii } & cutaneous/subcutaneous & $250 \mathrm{mg}$ twice daily & success & $|80,18|$ \\
\hline & & range: 8-37 weeks & & \\
\hline
\end{tabular}

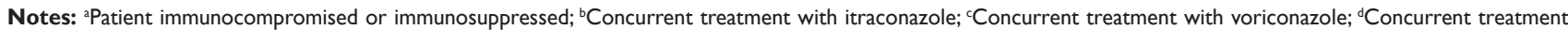
with amphotericin B; ${ }^{\mathrm{C} C o n c u r r e n t}$ treatment with ketoconazole. 
reported as a consequence of oral terbinafine use. It is estimated that $2.2 \%$ of patients treated with terbinafine will experience changes in their liver function tests. ${ }^{187}$ The onset typically occurs after 3 weeks of therapy and resolution can take as long as 3 months after discontinuation of the drug. While the majority of cases resolve following discontinuation of terbinafine, reports are available detailing patients that have progressed to liver transplantation and death. ${ }^{189,190}$ Notably, hepatic findings are not restricted to adults. An FDA review of the recently marketed terbinafine oral granule identified two cases, among 1042 children treated, of elevated transaminases leading to discontinuation of the drug. ${ }^{191}$ Terbinafine-induced acute autoimmune hepatitis has also been reported in a patient infected with hepatitis B virus. ${ }^{192,193}$

Blood dyscrasias including leucopenia, agranulocytosis, neutropenia and pancytopenia represent the other primary group of severe adverse drug reactions reported with terbinafine use. Most cases occur between weeks 4 to 5 of therapy and resolve within a week after stopping the medication. One fatality has been reported in a 79-year-old female who developed septic shock while being treated for terbinafine induced agranulocytosis. ${ }^{194}$ Among children receiving the new granule formulation, leucopenia and/or neutropenia was observed in 1.8\% (19/1042) of the children treated. ${ }^{191}$

Severe dermatologic eruptions including toxic epidermolysis, acute generalized exanthematous pustulosis, and Steven's Johnson syndrome have also been associated with terbinafine use. ${ }^{195}$ Recently, reports have also linked dermatomyositis and subacute cutaneous systemic lupus erythematosus to terbinafine. ${ }^{196,197}$ In one patient, a skin eruption presenting 4 weeks after the onset of therapy and occurring with the triad of fever, hepatic dysfunction and lymphadenopathy led investigators to conclude the presence of hypersensitivity syndrome. Resolution was experienced within 6 weeks of discontinuing the drug. ${ }^{198-203}$

An adverse effect unique to terbinafine is altered taste perception. Although numerous case reports have been published, there exist no reliable estimates of this side effect in patients taking terbinafine. ${ }^{204-210}$ Ageusia has taken up to 6 weeks to resolve, and was reported in association with loss of smell and discoloration of the tongue, in one patient each. ${ }^{208,210}$ Possible risk factors for developing terbinafine associated taste loss include an age greater than 65 years and a body mass index less than $21 \mathrm{~kg} / \mathrm{m}^{2}{ }^{211}$ Notably, a singular trial comparing terbinafine with griseofulvin for the treatment of tinea capitis, reported a change of eating habits in $4.7 \%$ and $5.5 \%$ of children, respectively. Whether, however, this was due to changes in taste perception is unknown. ${ }^{165}$

Of note, fewer patients receiving terbinafine pulse therapy as compared with traditional dosing experience elevations in liver enzymes or taste disturbances; however, the overall percentage of patients discontinuing therapy for adverse events was comparable between dosing strategies. ${ }^{124}$

While only a few reports exist, ocular side effects have been observed with oral terbinafine use. ${ }^{212-214}$ Bilateral anterior optic neuropathy with decreased vision and optic disc edema was reported in a patient 2 weeks after starting terbinafine $(500 \mathrm{mg} /$ day $) .{ }^{214}$ After discontinuing the medication his vision improved. Anterior uveitis was reported in a second patient with acquired immune deficiency syndrome after 12 days of therapy. As in the previous case, symptoms resolved with discontinuation of terbinafine. ${ }^{213}$

Among patients treated with topical terbinafine preparations, adverse events are primarily restricted to mild to moderate local skin reaction which may occur in as many as $6 \%$ of patients. ${ }^{99}$

\section{Conclusions}

Terbinafine is among the most commonly used antifungal agents for the treatment of dermatophyte infections of the skin and nails. The success experienced by this drug can, in large part, be attributed to its favorable mycologic and pharmacokinetic profiles. Terbinafine possesses many of the characteristics required of a drug used for infections where clinical resolution is largely dependent on the slow turnover of infected tissue, namely, excellent penetration at the site of infection and sustained fungicidal activity for extended durations after the discontinuation of therapy. Numerous clinical trials corroborate the suitability of terbinafine for the treatment of dermatophytoses with efficacy rates comparable to or greater than existing antifungals despite shorter treatment durations. While the role of terbinafine use in systemic mycoses has been limited to date, the agent may eventually find utility as an adjunctive agent in the management of recalcitrant infections. Although terbinafine is likely to remain the first-line agent for a number of dermatophyte infections, prescribers should remain cognizant of the infrequent but severe adverse reactions that have been observed (eg, agranulocytosis, hepatotoxicity) and the potential for significant drug-drug interactions with medications that rely on CYP2D6 as a primary route of metabolism. 


\section{Disclosures}

The authors disclose no conflicts of interest.

\section{References}

1. Brown M, Traynor M. Treatment of fungal nail infections. Drug Delivery Report. 2007(Spring/Summer):17-19.

2. Suh DC, Shin H, Raut M, Tavakkol A. Usage patterns of medical services and prescription drugs in patients with tinea capitis. J Am Acad Dermatol. 2004;50:86.

3. Birnbaum JE. Pharmacology of the allylamines. J Am Acad Dermatol. 1990;23(4 Pt 2):782-785.

4. Ganzinger U, Stutz A, Petranyi G, Stephen A. Allylamines: topical and oral treatment of dermatomycoses with a new class of antifungal agents. Acta Derm Venereol Suppl (Stockh). 1986;121:155-160.

5. Ryder NS. Specific inhibition of fungal sterol biosynthesis by SF 86-327, a new allylamine antimycotic agent. Antimicrob Agents Chemother. 1985;27(2):252-256.

6. Ryder NS. Terbinafine: mode of action and properties of the squalene epoxidase inhibition. Br J Dermatol. 1992;126 Suppl 39:2-7.

7. Ryder NS, Dupont MC. Inhibition of squalene epoxidase by allylamine antimycotic compounds. A comparative study of the fungal and mammalian enzymes. Biochem J. 1985;230(3):765-770.

8. Clayton YM. Relevance of broad-spectrum and fungicidal activity of antifungals in the treatment of dermatomycoses. $\mathrm{Br} J$ Dermatol. 1994;130 Suppl 43:7-8.

9. Dixon DM, Polak A. In vitro and in vivo drug studies with three agents of central nervous system phaeohyphomycosis. Chemotherapy. 1987;33(2):129-140.

10. Odds FC. Effects of temperature on anti-Candida activities of antifungal antibiotics. Antimicrob Agents Chemother. 1993;37(4):685-691.

11. Petranyi G, Meingassner JG, Mieth H. Activity of terbinafine in experimental fungal infections of laboratory animals. Antimicrob Agents Chemother. 1987;31(10):1558-1561.

12. Petranyi G, Meingassner JG, Mieth H. Antifungal activity of the allylamine derivative terbinafine in vitro. Antimicrob Agents Chemother. 1987;31(9):1365-1368.

13. Petranyi G, Ryder NS, Stutz A. Allylamine derivatives: new class of synthetic antifungal agents inhibiting fungal squalene epoxidase. Science. 1984;224(4654):1239-1241.

14. Schmitt HJ, Bernard EM, Andrade J, Edwards F, Schmitt B, Armstrong D. $\mathrm{MIC}$ and fungicidal activity of terbinafine against clinical isolates of Aspergillus spp. Antimicrob Agents Chemother. 1988;32(5):780-781.

15. Shadomy S, Espinel-Ingroff A, Gebhart RJ. In-vitro studies with SF 86-327, a new orally active allylamine derivative. Sabouraudia. 1985;23(2):125-132.

16. Venugopal PV, Venugopal TV. Antidermatophytic activity of allylamine derivatives. Indian J Pathol Microbiol. 1994;37(4):381-388.

17. Standards NCfCL. Reference method for broth dilution antifungal susceptibility testing of filamentous fungi. Approved Standard. NCCLS document M38-A2. Wayne, PA: Clinical and Laboratory Standards Institute; 2008.

18. Goh CL, Tay YK, Ali KB, Koh MT, Seow CS. In vitro evaluation of griseofulvin, ketoconazole, and itraconazole against various dermatophytes in Singapore. Int J Dermatol. 1994;33(10):733-737.

19. Grant SM, Clissold SP. Itraconazole. A review of its pharmacodynamic and pharmacokinetic properties, and therapeutic use in superficial and systemic mycoses. Drugs. 1989;37(3):310-344.

20. Heel RC, Brogden RN, Carmine A, Morley PA, Speight TM, Avery GS. Ketoconazole: a review of its therapeutic efficacy in superficial and systemic fungal infections. Drugs. 1982;23(1-2):1-36.

21. Howard R, Aly R, Frieden I. Analysis of trychophyton tonsurans sensitivity to griseofulvin in vitro (abstract). Clin Res. 1993;41:420A.

22. Venugopal PV, Venugopal TV. Disk diffusion susceptibility testing of dermatophytes with allylamines. Int J Dermatol. 1994;33(10):730-732.

23. Venugopal PV, Venugopal TV. Antidermatophytic activity of garlic (Allium sativum) in vitro. Int J Dermatol. 1995;34(4):278-279.
24. da Silva Barros ME, de Assis Santos D, Hamdan JS. Evaluation of susceptibility of Trichophyton mentagrophytes and Trichophyton rubrum clinical isolates to antifungal drugs using a modified CLSI microdilution method (M38-A). J Med Microbiol. 2007;56(Pt 4):514-518.

25. Ghannoum MA, Wraith LA, Cai B, Nyirady J, Isham N. Susceptibility of dermatophyte isolates obtained from a large worldwide terbinafine tinea capitis clinical trial. Br J Dermatol. 2008;159(3):711-713.

26. Coelho LM, Aquino-Ferreira R, Maffei CM, Martinez-Rossi NM. In vitro antifungal drug susceptibilities of dermatophytes microconidia and arthroconidia. J Antimicrob Chemother. 2008;62(4):758-761.

27. Zeng YB, Qian YS, Ma L, Gu HN. Genome-wide expression profiling of the response to terbinafine in Candida albicans using a cDNA microarray analysis. Chin Med J (Engl). 2007;120(9):807-813.

28. Cervelatti EP, Fachin AL, Ferreira-Nozawa MS, Martinez-Rossi NM. Molecular cloning and characterization of a novel ABC transporter gene in the human pathogen Trichophyton rubrum. Med Mycol. 2006;44(2):141-147.

29. Graminha MA, Rocha EM, Prade RA, Martinez-Rossi NM. Terbinafine resistance mediated by salicylate 1-monooxygenase in Aspergillus nidulans. Antimicrob Agents Chemother. 2004;48(9):3530-3535.

30. Osborne CS, Hofbauer B, Favre B, Ryder NS. In vitro analysis of the ability of Trichophyton rubrum to become resistant to terbinafine. Antimicrob Agents Chemother. 2003;47(11):3634-3636.

31. Osborne CS, Leitner I, Favre B, Ryder NS. Amino acid substitution in Trichophyton rubrum squalene epoxidase associated with resistance to terbinafine. Antimicrob Agents Chemother. 2005;49(7):2840-2844.

32. Osborne CS, Leitner I, Hofbauer B, Fielding CA, Favre B, Ryder NS. Biological, biochemical, and molecular characterization of a new clinical Trichophyton rubrum isolate resistant to terbinafine. Antimicrob Agents Chemother. 2006;50(6):2234-2236.

33. Rocha EM, Almeida CB, Martinez-Rossi NM. Identification of genes involved in terbinafine resistance in Aspergillus nidulans. Lett Appl Microbiol. 2002;35(3):228-232.

34. Martinez-Rossi NM, Peres NT, Rossi A. Antifungal resistance mechanisms in dermatophytes. Mycopathologia. 2008;166(5-6):369-383.

35. Schuetzer-Muehlbauer M, Willinger B, Krapf G, Enzinger S, Presterl E, Kuchler K. The Candida albicans Cdr2p ATP-binding cassette (ABC) transporter confers resistance to caspofungin. Mol Microbiol. 2003;48(1):225-235.

36. Kohli A, Smriti, Mukhopadhyay K, Rattan A, Prasad R. In vitro low-level resistance to azoles in Candida albicans is associated with changes in membrane lipid fluidity and asymmetry. Antimicrob Agents Chemother. 2002;46(4):1046-1052.

37. Magaldi S, Mata S, Hartung C, Verde G, Deibis L, Roldan Y, et al. In vitro susceptibility of 137 Candida sp isolates from HIV positive patients to several antifungal drugs. Mycopathologia. 2001;149(2):63-68.

38. vanden Bossche H, Marichal P, Odds FC, Le Jeune L, Coene MC. Characterization of an azole-resistant Candida glabrata isolate. Antimicrob Agents Chemother. 1992;36(12):2602-2610.

39. Ryder NS, Leitner I. Activity of terbinafine against Aspergillus in vitro, in combination with amphotericin B or triazoles (Abstract E54). 36th Interscience Conference on Antimicrobial Agents and Chemotherapy; 1996 Sept 15-18; New Orleans, LA. 1996.

40. Fothergill AW, Leitner I, Meingassner JG, Ryder NS, Rinaldi MG. Combination antifungal susceptibility testing of terbinafine and the triazoles fluconazole and itraconazole (Abstract E53). 36th Interscience Conference on Antimicrobial Agents and Chemotherapy; 1996 September 15-18; New Orleans, LA. 1996.

41. Rodero L, Vitale R, Hochenfellner F, Canteos C, Davel G. In vitro activity of terbinafine in combination with triazole drugs against fluconazole resistant candida species (Abstract E56). . 36th Interscience Conference on Antimicrobial Agents and Chemotherapy; 1996 September 15-18; New Orleans, LA. 1996.

42. Li L, Wang Z, Li R, Luo S, Sun X. In vitro evaluation of combination antifungal activity against Fusarium species isolated from ocular tissues of keratomycosis patients. Am J Ophthalmol. 2008;146(5): 724-728. 
43. Abdel-Rahman SM, Herron J, Fallon-Friedlander S, Hauffe S, Horowitz A, Riviere GJ. Pharmacokinetics of terbinafine in young children treated for tinea capitis. Pediatr Infect Dis J. 2005;24(10):886-891.

44. Nejjam F, Zagula M, Cabiac MD, Guessous N, Humbert H, Lakhdar H. Pilot study of terbinafine in children suffering from tinea capitis: evaluation of efficacy, safety and pharmacokinetics. $\mathrm{Br} J$ Dermatol. 1995;132(1):98-105.

45. Jiang X, Wang N, Zhang ZJ, Tian Y, Chen Y. Pharmacokinetics and comparative bioavailability of two terbinafine hydrochloride formulations after single-dose administration in Chinese healthy subjects. Arzneimittelforschung. 2008;58(7):363-366.

46. Kovarik JM, Mueller EA, Zehender H, Denouel J, Caplain H, Millerioux L. Multiple-dose pharmacokinetics and distribution in tissue of terbinafine and metabolites. Antimicrob Agents Chemother. 1995;39(12):2738-2741.

47. Faergemann J, Zehender H, Denouel J, Millerioux L. Levels of terbinafine in plasma, stratum corneum, dermis-epidermis (without stratum corneum), sebum, hair and nails during and after $250 \mathrm{mg}$ terbinafine orally once per day for four weeks. Acta Derm Venereol. 1993;73(4):305-309.

48. Cramer J, Kshatriya B, Snoddy A. Skin pharmacokinetics of terbinafine in healthy subjects following once-daily application of $1 \%$ emulsion gel or $1 \%$ cream for 1,5 , or 7 days. American College of Clinical Pharmacy Annual Meeting; 2006 October 26; St. Louis, MO. 2006.

49. Denouell J, Burtin P, Kshatriya B, Snoddy A. Pharmacokinetics of terbinafine $1 \%$ emulsion gel in healthy volunteers and in patients with tinea cruris/corporis. American College of Clinical Pharmacy Annual Meeting; 2006; St. Louis, MO. 2006. p. October 26.

50. Kienzler JL, Queille-Roussel C, Mugglestone C, Ortonne JP, Larnier C. Stratum corneum pharmacokinetics of the anti-fungal drug, terbinafine, in a novel topical formulation, for single-dose application in dermatophytoses. Curr Med Res Opin. 2007;23(6):1293-1302.

51. Gupta AK, Sauder DN, Shear NH. Antifungal agents: an overview. Part II. J Am Acad Dermatol. 1994;30(6):911-33; quiz 34-6.

52. Jensen JC. Clinical pharmacokinetics of terbinafine (Lamisil). Clin Exp Dermatol. 1989;14(2):110-113.

53. Kovarik JM, Kirkesseli S, Humbert H, Grass P, Kutz K. Dose-proportional pharmacokinetics of terbinafine and its N-demethylated metabolite in healthy volunteers. Br J Dermatol. 1992;126 Suppl 39:8-13.

54. Hill S, Thomas R, Smith SG, Finlay AY. An investigation of the pharmacokinetics of topical terbinafine (Lamisil) $1 \%$ cream. Br J Dermatol. 1992;127(4):396-400

55. Tanuma H, Doi M, Ohta Y, Nishiyama S, Katsuoka K, Kaneko S, et al. Usefulness of $1 \%$ terbinafine $\mathrm{HCl}$ (Lamisil) cream for hyperkeratotic-type tinea pedis and its transfer into the horny layer. Mycoses. 2000;43(11-12):417-432.

56. Jensen JC. Pharmacokinetics of Lamisil in humans. J Dermatol Treat. 1990;1 Suppl 2:15-18.

57. Ryder NS, Frank I. Interaction of terbinafine with human serum and serum proteins. J Med Vet Mycol. 1992;30(6):451-460.

58. Kikuchi I, Tanuma H, Morimoto K, Kawana S. Usefulness and pharmacokinetic study of oral terbinafine for hyperkeratotic type tinea pedis. Mycoses. 2008;51(1):7-13.

59. Humbert H, Cabiac MD, Denouel J, Kirkesseli S. Pharmacokinetics of terbinafine and of its five main metabolites in plasma and urine, following a single oral dose in healthy subjects. Biopharm Drug Dispos. 1995;16(8):685-694.

60. Abdel-Rahman SM, Marcucci K, Boge T, Gotschall RR, Kearns GL, Leeder JS. Potent inhibition of cytochrome P-450 2D6-mediated dextromethorphan O-demethylation by terbinafine. Drug Metab Dispos. 1999;27(7):770-775.

61. Back DJ, Tjia JF, Abel SM. Azoles, allylamines and drug metabolism. Br J Dermatol. 1992;126 Suppl 39:14-18.

62. Schuster I. The interaction of representative members from two classes of antimycotics--the azoles and the allylamines--with cytochromes P-450 in steroidogenic tissues and liver. Xenobiotica. 1985;15(6): 529-546.
63. Vickers AE, Sinclair JR, Zollinger M, Heitz F, Glanzel U, Johanson L, et al. Multiple cytochrome P-450s involved in the metabolism of terbinafine suggest a limited potential for drug-drug interactions. Drug Metab Dispos. 1999;27(9):1029-1038.

64. Abdel-Rahman SM, Gotschall RR, Kauffman RE, Leeder JS, Kearns GL. Investigation of terbinafine as a CYP2D6 inhibitor in vivo. Clin Pharmacol Ther. 1999;65(5):465-472.

65. Castberg I, Helle J, Aamo TO. Prolonged pharmacokinetic drug interaction between terbinafine and amitriptyline. Ther Drug Monit. 2005;27(5):680-682.

66. Hynninen VV, Olkkola KT, Bertilsson L, Kurkinen K, Neuvonen PJ, Laine K. Effect of terbinafine and voriconazole on the pharmacokinetics of the antidepressant venlafaxine. Clin Pharmacol Ther. 2008;83(2): 342-348.

67. Madani S, Barilla D, Cramer J, Wang Y, Paul C. Effect of terbinafine on the pharmacokinetics and pharmacodynamics of desipramine in healthy volunteers identified as cytochrome P450 2D6 (CYP2D6) extensive metabolizers. J Clin Pharmacol. 2002;42(11):1211-1218.

68. van der Kuy PH, Hooymans PM. Nortriptyline intoxication induced by terbinafine. BMJ. 1998;316(7129):441.

69. Venkatakrishnan K, von Moltke LL, Greenblatt DJ. Effects of the antifungal agents on oxidative drug metabolism: clinical relevance. Clin Pharmacokinet. 2000;38(2):111-180.

70. Lamisil Package Insert. Sandoz Pharmaceutical Corporation. 1996.

71. Ahonen J, Olkkola KT, Neuvonen PJ. Effect of itraconazole and terbinafine on the pharmacokinetics and pharmacodynamics of midazolam in healthy volunteers. Br J Clin Pharmacol. 1995;40(3): 270-272.

72. Back DJ, Stevenson P, Tjia JF. Comparative effects of two antimycotic agents, ketoconazole and terbinafine on the metabolism of tolbutamide, ethinyloestradiol, cyclosporin and ethoxycoumarin by human liver microsomes in vitro. Br J Clin Pharmacol. 1989;28(2):166-170.

73. Seyffer R, Eichelbaum M, Jensen JC, Klotz U. Antipyrine metabolism is not affected by terbinafine, a new antifungal agent. Eur J Clin Pharmacol. 1989;37(3):231-233.

74. Shah IA, Whiting PH, Omar G, Ormerod AD, Burke MD. The effects of retinoids and terbinafine on the human hepatic microsomal metabolism of cyclosporin. Br J Dermatol. 1993;129(4):395-398.

75. Breckenridge A. Clinical significance of interactions with antifungal agents. Br J Dermatol. 1992;126 Suppl 39:19-22.

76. Zehender H, Cabiac MD, Denouel J, Faergemann J, Donatsch P, Kutz K, et al. Elimination kinetics of terbinafine from human plasma and tissue following multiple-dose administration, and comparison with 3 main metabolites. Drug Invest. 1994;8:203-210.

77. Odom R. Pathophysiology of dermatophyte infections. J Am Acad Dermatol. 1993;28(5 Pt 1):S2-S7.

78. Farag A, Taha M, Halim S. One-week therapy with oral terbinafine in cases of tinea cruris/corporis. Br J Dermatol. 1994;131(5):684-686.

79. Evans EG, Seaman RA, James IG. Short-duration therapy with terbinafine $1 \%$ cream in dermatophyte skin infections. Br J Dermatol. 1994;130(1):83-87.

80. Bonifaz A, Saul A. Comparative study between terbinafine $1 \%$ emulsion-gel versus ketoconazole $2 \%$ cream in tinea cruris and tinea corporis. Eur J Dermatol. 2000;10(2):107-109.

81. Budimulja U, Bramono K, Urip KS, Basuki S, Widodo G, Rapatz G, et al. Once daily treatment with terbinafine $1 \%$ cream (Lamisil) for one week is effective in the treatment of tinea corporis and cruris. A placebo-controlled study. Mycoses. 2001;44(7-8):300-306.

82. Greer DL, Jolly HW Jr. Treatment of tinea cruris with topical terbinafine. J Am Acad Dermatol. 1990;23(4 Pt 2):800-804.

83. Lebwohl M, Elewski B, Eisen D, Savin RC. Efficacy and safety of terbinafine $1 \%$ solution in the treatment of interdigital tinea pedis and tinea corporis or tinea cruris. Cutis. 2001;67(3):261-266.

84. Ledezma E, Lopez JC, Marin P, Romero H, Ferrara G, De Sousa L, et al. Ajoene in the topical short-term treatment of tinea cruris and tinea corporis in humans. Randomized comparative study with terbinafine. Arzneimittelforschung. 1999;49(6):544-547. 
85. Millikan LE. Efficacy and tolerability of topical terbinafine in the treatment of tinea cruris. J Am Acad Dermatol. 1990;23(4 Pt 2):795-799.

86. Zaias N, Berman B, Cordero CN, Hernandez A, Jacobson C, Millikan L, et al. Efficacy of a 1-week, once-daily regimen of terbinafine $1 \%$ cream in the treatment of tinea cruris and tinea corporis. J Am Acad Dermatol. 1993;29(4):646-648.

87. Cole GW, Stricklin G. A comparison of a new oral antifungal, terbinafine, with griseofulvin as therapy for tinea corporis. Arch Dermatol. 1989;125(11):1537-1539.

88. del Palacio Hernandez A, Lopez Gomez S, Gonzalez Lastra F, Moreno Palancar P, Iglesias Diez L. A comparative double-blind study of terbinafine (Lamisil) and griseofulvin in tinea corporis and tinea cruris. Clin Exp Dermatol. 1990;15(3):210-216.

89. Voravutinon V. Oral treatment of tinea corporis and tinea cruris with terbinafine and griseofulvin: a randomized double blind comparative study. J Med Assoc Thai. 1993;76(7):388-393.

90. Budimulja U, Kuswadji K, Bramono S, Basuki J, Judanarso LS, Untung S, et al. A double-blind, randomized, stratified controlled study of the treatment of tinea imbricata with oral terbinafine or itraconazole. Br J Dermatol. 1994;130 Suppl 43:29-31.

91. Shrum JP, Millikan LE, Bataineh O. Superficial fungal infections in the tropics. Dermatol Clin. 1994;12(4):687-693.

92. Elewski B, Nagashima-Whalen L. Superficial fungal infections of the skin. In: Hoeprich PD, Jordan MC, Ronald AR, editors. Infectious Diseases- A treatise of infectious processes. 5th ed. Philadelphia, PA: JB Lippincott Company; 1994. p. 1029-1049.

93. Hollmen KA, Kinnunen T, Kiistala U, Vaananen A, Saarelainen IO, De CC, et al. Efficacy and tolerability of terbinafine 1\% emulsion gel in patients with tinea pedis. $J$ Eur Acad Dermatol Venereol. 2002; 16(1):87-88.

94. James IG, Loria-Kanza Y, Jones TC. Short-duration topical treatment of tinea pedis using terbinafine emulsion gel: results of a dose-ranging clinical trial. J Dermatolog Treat. 2007;18(3):163-8.

95. Korting HC, Tietz HJ, Brautigam M, Mayser P, Rapatz G, Paul C. One week terbinafine $1 \%$ cream (Lamisil) once daily is effective in the treatment of interdigital tinea pedis: a vehicle controlled study. LAS-INT-06 Study Group. Med Mycol. 2001;39(4):335-340.

96. Ledezma E, Marcano K, Jorquera A, De Sousa L, Padilla M, Pulgar M, et al. Efficacy of ajoene in the treatment of tinea pedis: a doubleblind and comparative study with terbinafine. J Am Acad Dermatol. 2000;43(5 Pt 1):829-832.

97. Leenutaphong V, Niumpradit N, Tangwiwat S, Sritaveesuwan R, Muanprasat C. Double-blind study of the efficacy of 1 week topical terbinafine cream compared to 4 weeks miconazole cream in patients with tinea pedis. J Med Assoc Thai. 1999;82(10):1006-1010.

98. Patel A, Brookman SD, Bullen MU, Marley J, Ellis DH, Williams T, et al. Topical treatment of interdigital tinea pedis: terbinafine compared with clotrimazole. Australas J Dermatol. 1999;40(4):197-200.

99. Schopf R, Hettler O, Brautigam M, Weidinger G, Kaben U, Mayser P, et al. Efficacy and tolerability of terbinafine $1 \%$ topical solution used for 1 week compared with 4 weeks clotrimazole $1 \%$ topical solution in the treatment of interdigital tinea pedis: a randomized, doubleblind, multi-centre, 8-week clinical trial. Mycoses. 1999;42(5-6): 415-420.

100. de Chauvin MF, Viguie-Vallanet C, Kienzler JL, Larnier C. Novel, single-dose, topical treatment of tinea pedis using terbinafine: results of a dose-finding clinical trial. Mycoses. 2008;51(1):1-6.

101. Ortonne JP, Korting HC, Viguie-Vallanet C, Larnier C, Savaluny E. Efficacy and safety of a new single-dose terbinafine $1 \%$ formulation in patients with tinea pedis (athlete's foot): a randomized, double-blind, placebo-controlled study. J Eur Acad Dermatol Venereol. 2006;20(10): 1307-1313.

102. Savin R. Successful treatment of chronic tinea pedis (moccasin type) with terbinafine (Lamisil). Clin Exp Dermatol. 1989;14(2):116-119.

103. Savin RC, Zaias N. Treatment of chronic moccasin-type tinea pedis with terbinafine: a double-blind, placebo-controlled trial. $\mathrm{J} \mathrm{Am} \mathrm{Acad}$ Dermatol. 1990;23(4 Pt 2):804-807.
104. De Keyser P, De Backer M, Massart DL, Westelinck KJ. Two-week oral treatment of tinea pedis, comparing terbinafine $(250 \mathrm{mg} /$ day $)$ with itraconazole $(100 \mathrm{mg} /$ day): a double-blind, multicentre study. Br J Dermatol. 1994;130 Suppl 43:22-25.

105. Hay RJ, McGregor JM, Wuite J, Ryatt KS, Ziegler C, Clayton YM. A comparison of 2 weeks of terbinafine $250 \mathrm{mg}$ /day with 4 weeks of itraconazole $100 \mathrm{mg} /$ day in plantar-type tinea pedis. Br J Dermatol. 1995;132(4):604-608.

106. Scher RK. Onychomycosis is more than a cosmetic problem. $\mathrm{Br} J$ Dermatol. 1994;130 Suppl 43:15.

107. Degreef H. Onychomycosis. Br J Clin Pract Suppl. 1990;71:91-97.

108. Midgley G, Moore MK, Cook JC, Phan QG. Mycology of nail disorders. J Am Acad Dermatol. 1994;31(3 Pt 2):S68-74.

109. Baudraz-Rosselet F, Rakosi T, Wili PB, Kenzelmann R. Treatment of onychomycosis with terbinafine. Br J Dermatol. 1992;126 Suppl 39:40-46.

110. Farkas B, Paul C, Dobozy A, Hunyadi J, Horvath A, Fekete G. Terbinafine (Lamisil) treatment of toenail onychomycosis in patients with insulin-dependent and non-insulin-dependent diabetes mellitus: a multicentre trial. Br J Dermatol. 2002;146(2):254-260.

111. Goodfield MJ, Andrew L, Evans EG. Short term treatment of dermatophyte onychomycosis with terbinafine. BMJ. 1992;304(6835):1151-1154.

112. Pollak R, Billstein SA. Efficacy of terbinafine for toenail onychomycosis. A multicenter trial of various treatment durations. J Am Podiatr Med Assoc. 2001;91(3):127-131.

113. Watson A, Marley J, Ellis D, Williams T. Terbinafine in onychomycosis of the toenail: a novel treatment protocol. J Am Acad Dermatol. 1995;33(5 Pt 1):775-779.

114. Zaias N, Serrano L. The successful treatment of finger Trichophyton rubrum onychomycosis with oral terbinafine. Clin Exp Dermatol. 1989;14(2):120-123.

115. Gupta AK, Gregurek-Novak T. Efficacy of itraconazole, terbinafine, fluconazole, griseofulvin and ketoconazole in the treatment of Scopulariopsis brevicaulis causing onychomycosis of the toes. Dermatology. 2001;202(3):235-238.

116. Warshaw EM, Nelson D, Carver SM, Zielke GR, Webster N, Lederle FA, et al. A pilot evaluation of pulse itraconazole vs terbinafine for treatment of Candida toenail onychomycosis. Int J Dermatol. 2005;44(9):785-788.

117. Wong CK, Cho YL. Very short duration therapy with oral terbinafine for fingernail onychomycosis. Br J Dermatol. 1995;133(2):329-331.

118. Albanese G, Di Cintio R, Martini C, Nicoletti A. Short therapy for tinea unguium with terbinafine: four different courses of treatment. Mycoses. 1995;38(5-6):211-214.

119. Jennings MB, Pollak R, Harkless LB, Kianifard F, Tavakkol A. Treatment of toenail onychomycosis with oral terbinafine plus aggressive debridement: IRON-CLAD, a large, randomized, open-label, multicenter trial. J Am Podiatr Med Assoc. 2006;96(6):465-473.

120. Avner S, Nir N, Henri T. Combination of oral terbinafine and topical ciclopirox compared to oral terbinafine for the treatment of onychomycosis. J Dermatolog Treat. 2005;16(5-6):327-330.

121. Baran R. Topical amorolfine for 15 months combined with 12 weeks of oral terbinafine, a cost-effective treatment for onychomycosis. Br J Dermatol. 2001;145 Suppl 60:15-19.

122. Baran R, Sigurgeirsson B, de Berker D, Kaufmann R, Lecha M, Faergemann J, et al. A multicentre, randomized, controlled study of the efficacy, safety and cost-effectiveness of a combination therapy with amorolfine nail lacquer and oral terbinafine compared with oral terbinafine alone for the treatment of onychomycosis with matrix involvement. Br J Dermatol. 2007;157(1):149-157.

123. Gupta AK. Ciclopirox topical solution, $8 \%$ combined with oral terbinafine to treat onychomycosis: a randomized, evaluator-blinded study. J Drugs Dermatol. 2005;4(4):481-485.

124. Sigurgeirsson B, Elewski BE, Rich PA, Opper C, Cai B, Nyirady J, et al. Intermittent versus continuous terbinafine in the treatment of toenail onychomycosis: a randomized, double-blind comparison. J Dermatolog Treat. 2006;17(1):38-44. 
125. Warshaw EM, Fett DD, Bloomfield HE, Grill JP, Nelson DB, Quintero V, et al. Pulse versus continuous terbinafine for onychomycosis: a randomized, double-blind, controlled trial. $J$ Am Acad Dermatol. 2005;53(4):578-584.

126. Nakano N, Hiruma M, Shiraki Y, Chen X, Porgpermdee S, Ikeda S. Combination of pulse therapy with terbinafine tablets and topical terbinafine cream for the treatment of dermatophyte onychomycosis: a pilot study. J Dermatol. 2006;33(11):753-758.

127. Jaiswal A, Sharma RP, Garg AP. An open randomized comparative study to test the efficacy and safety of oral terbinafine pulse as a monotherapy and in combination with topical ciclopirox olamine $8 \%$ or topical amorolfine hydrochloride $5 \%$ in the treatment of onychomycosis. Indian J Dermatol Venereol Leprol. 2007;73(6): 393-396.

128. Takahata Y, Hiruma M, Shiraki Y, Tokuhisa Y, Sugita T, Muto M. Treatment of dermatophyte onychomycosis with three pulses of terbinafine (500 mg day for a week). Mycoses. 2009;52(1):72-76.

129. Faergemann J, Anderson C, Hersle K, Hradil E, Nordin P, Kaaman T, et al. Double-blind, parallel-group comparison of terbinafine and griseofulvin in the treatment of toenail onychomycosis. $J$ Am Acad Dermatol. 1995;32(5 Pt 1):750-753.

130. Haneke E, Tausch I, Brautigam M, Weidinger G, Welzel D. Shortduration treatment of fingernail dermatophytosis: a randomized, double-blind study with terbinafine and griseofulvin. LAGOS III Study Group. J Am Acad Dermatol. 1995;32(1):72-77.

131. Hofmann H, Brautigam M, Weidinger G, Zaun H. Treatment of toenail onychomycosis. A randomized, double-blind study with terbinafine and griseofulvin. LAGOS II Study Group. Arch Dermatol. 1995;131(8):919-922.

132. Arenas R, Dominguez-Cherit J, Fernandez LM. Open randomized comparison of itraconazole versus terbinafine in onychomycosis. Int J Dermatol. 1995;34(2):138-143.

133. Brautigam M, Nolting S, Schopf RE, Weidinger G. Randomised double blind comparison of terbinafine and itraconazole for treatment of toenail tinea infection. Seventh Lamisil German Onychomycosis Study Group. BMJ. 1995;311(7010):919-922.

134. Degreef H, del Palacio A, Mygind S, Ginter G, Pinto Soares A, Zuluaga de Cadena A. Randomized double-blind comparison of short-term itraconazole and terbinafine therapy for toenail onychomycosis. Acta Derm Venereol. 1999;79(3):221-223.

135. Arca E, Tastan HB, Akar A, Kurumlu Z, Gur AR. An open, randomized, comparative study of oral fluconazole, itraconazole and terbinafine therapy in onychomycosis. $J$ Dermatolog Treat. 2002;13(1):3-9.

136. Gupta AK, Gover MD, Lynde CW. Pulse itraconazole vs continuous terbinafine for the treatment of dermatophyte toenail onychomycosis in patients with diabetes mellitus. $J$ Eur Acad Dermatol Venereol. 2006;20(10):1188-1193.

137. Kejda J. Itraconazole pulse therapy vs continuous terbinafine dosing for toenail onychomycosis. Postgrad Med. 1999; Spec No:12-15.

138. Mishra M, Panda P, Tripathy S, Sengupta S, Mishra K. An open randomized comparative study of oral itraconazole pulse and terbinafine pulse in the treatment of onychomycosis. Indian J Dermatol Venereol Leprol. 2005;71(4):262-266.

139. Sigurgeirsson B, Billstein S, Rantanen T, Ruzicka T, di Fonzo E, Vermeer BJ, et al. L.I.ON. Study: efficacy and tolerability of continuous terbinafine (Lamisil) compared to intermittent itraconazole in the treatment of toenail onychomycosis. Lamisil vs Itraconazole in Onychomycosis. Br J Dermatol. 1999;141 Suppl 56:5-14.

140. Heikkila H, Stubb S. Long-term results in patients with onychomycosis treated with terbinafine or itraconazole. $\mathrm{Br} J$ Dermatol. 2002;146(2):250-253.

141. Sigurgeirsson B, Olafsson JH, Steinsson JB, Paul C, Billstein S, Evans EG. Long-term effectiveness of treatment with terbinafine vs itraconazole in onychomycosis: a 5-year blinded prospective follow-up study. Arch Dermatol. 2002;138(3):353-357.
142. Havu V, Heikkila H, Kuokkanen K, Nuutinen M, Rantanen T, Saari S, et al. A double-blind, randomized study to compare the efficacy and safety of terbinafine (Lamisil) with fluconazole (Diflucan) in the treatment of onychomycosis. Br J Dermatol. 2000;142(1):97-102.

143. Baran R, de Doncker P. Lateral edge nail involvement indicates poor prognosis for treating onychomycosis with the new systemic antifungals. Acta Derm Venereol. 1996;76(1):82-83.

144. Sigurgeirsson B, Paul C, Curran D, Evans EG. Prognostic factors of mycological cure following treatment of onychomycosis with oral antifungal agents. Br J Dermatol. 2002;147(6):1241-1243.

145. Sommer S, Sheehan-Dare RA, Goodfield MJ, Evans EG. Prediction of outcome in the treatment of onychomycosis. Clin Exp Dermatol. 2003;28(4):425-428.

146. Roberts DT, Evans EG. Subungual dermatophytoma complicating dermatophyte onychomycosis. Br J Dermatol. 1998;138(1):189-190.

147. O'Brien JM. Common skin problems of infancy, childhood, and adolescence. Prim Care. 1995;22(1):99-115.

148. Abdel-Rahman SM, Nahata MC, Powell DA. Response to initial griseofulvin therapy in pediatric patients with tinea capitis. Ann Pharmacother. 1997;31(4):406-410.

149. Bronson DM, Desai DR, Barsky S, Foley SM. An epidemic of infection with Trichophyton tonsurans revealed in a 20-year survey of fungal infections in Chicago. J Am Acad Dermatol. 1983;8(3):322-330.

150. Laude TA, Shah BR, Lynfield Y. Tinea capitis in Brooklyn. Am J Dis Child. 1982;136(12):1047-1050.

151. Prevost E. Nonfluorescent tinea capitis in Charleston, SC. A diagnostic problem. JAMA. 1979;242(16):1765-1767.

152. Friedlander SF, Aly R, Krafchik B, Blumer J, Honig P, Stewart D, et al. Terbinafine in the treatment of Trichophyton tinea capitis: a randomized, double-blind, parallel-group, duration-finding study. Pediatrics. 2002;109(4):602-607.

153. Hamm H, Schwinn A, Brautigam M, Weidinger G. Short duration treatment with terbinafine for tinea capitis caused by Trichophyton or Microsporum species. The Study Group. Br J Dermatol. 1999;140(3):480-482.

154. Haroon TS, Hussain I, Mahmood A, Nagi AH, Ahmad I, Zahid M. An open clinical pilot study of the efficacy and safety of oral terbinafine in dry non-inflammatory tinea capitis. Br J Dermatol. 1992;126 Suppl 39:47-50.

155. Krafchik B, Pelletier J. An open study of tinea capitis in 50 children treated with a 2-week course of oral terbinafine. J Am Acad Dermatol. 1999;41(1):60-63.

156. Aste N, Pau M. Tinea capitis caused by Microsporum canis treated with terbinafine. Mycoses. 2004;47(9-10):428-430.

157. Koumantaki E, Kakourou T, Rallis E, Riga P, Georgalla S. Doubled dose of oral terbinafine is required for Microsporum canis tinea capitis. Pediatr Dermatol. 2001;18(4):339-342.

158. Silm H, Karelson M. Terbinafine: efficacy and tolerability in young children with tinea capitis due to Microsporum canis. J Eur Acad Dermatol Venereol. 2002;16(3):228-230.

159. Alvi KH, Iqbal N, Khan KA, Haroon TS, Hussain I, Aman S, et al. A randomized double-blind trial of the efficacy and tolerability of terbinafine once daily compared to griseofulvin once daily in the treatment of tinea capitis. In: Shuster S, Jafary MH, editors. Royal Society of Medicine Services International Congress Series; 1992. p. 35-40.

160. Caceres-Rios H, Rueda M, Ballona R, Bustamante B. Comparison of terbinafine and griseofulvin in the treatment of tinea capitis. $J \mathrm{Am}$ Acad Dermatol. 2000;42(1 Pt 1):80-84.

161. Fuller LC, Smith CH, Cerio R, Marsden RA, Midgley G, Beard AL, et al. A randomized comparison of 4 weeks of terbinafine vs 8 weeks of griseofulvin for the treatment of tinea capitis. Br J Dermatol. 2001;144(2):321-327.

162. Lipozencic J, Skerlev M, Orofino-Costa R, Zaitz VC, Horvath A, Chouela E, et al. A randomized, double-blind, parallel-group, durationfinding study of oral terbinafine and open-label, high-dose griseofulvin in children with tinea capitis due to Microsporum species. $\mathrm{Br} J$ Dermatol. 2002;146(5):816-823. 
163. Ungpakorn R, Ayutyanont T, Reangchainam S, Supanya S. Treatment of Microsporum spp. tinea capitis with pulsed oral terbinafine. Clin Exp Dermatol. 2004;29(3):300-303.

164. Gupta AK, Adam P, Dlova N, Lynde CW, Hofstader S, Morar N, et al. Therapeutic options for the treatment of tinea capitis caused by Trichophyton species: griseofulvin versus the new oral antifungal agents, terbinafine, itraconazole, and fluconazole. Pediatr Dermatol. 2001;18(5):433-438.

165. Elewski BE, Caceres HW, DeLeon L, El Shimy S, Hunter JA, Korotkiy N, et al. Terbinafine hydrochloride oral granules versus oral griseofulvin suspension in children with tinea capitis: results of two randomized, investigator-blinded, multicenter, international, controlled trials. J Am Acad Dermatol. 2008;59(1):41-54.

166. Faergemann J, Zehender H, Boukhabza A, Smith SG, Jones TC. A double-blind comparison of levels of terbinafine and itraconazole in plasma, skin, sebum, hair and nails during and after oral medication. Acta Derm Venereol. 1997;77(1):74-76.

167. Jung EG, Haas PJ, Brautigam M, Weidinger G. Systemic treatment of skin candidosis: a randomized comparison of terbinafine and ketoconazole. Mycoses. 1994;37(9-10):361-365.

168. Gianni C, Romano C. Clinical and histological aspects of toenail onychomycosis caused by Aspergillus spp: 34 cases treated with weekly intermittent terbinafine. Dermatology. 2004;209(2):104-110.

169. Li DM, Xiu DR, Li RY, Samson RA, de Hoog GS, Wang DL. Aspergillus flavus myositis in a patient after liver transplantation. Clin Transplant. 2008;22(4):508-511.

170. Krishnan-Natesana S, Chandrasekara PH, Manavathua EK, Revankar SG. Successful treatment of primary cutaneous Aspergillus ustus infection with surgical debridement and a combination of voriconazole and terbinafine. Diagn Microbiol Infect Dis. 2008;62(4):443-446.

171. Esterre P, Inzan CK, Ramarcel ER, Andriantsimahavandy A, Ratsioharana M, Pecarrere JL, et al. Treatment of chromomycosis with terbinafine: preliminary results of an open pilot study. Br J Dermatol. 1996;134 Suppl 46:33-36; discussion 40.

172. Xibao Z, Changxing L, Quan L, Yuqing H. Treatment of chromoblastomycosis with terbinafine: a report of four cases. J Dermatolog Treat. 2005;16(2):121-124.

173. Bryan CS, Smith CW, Berg DE, Karp RB. Curvularia lunata endocarditis treated with terbinafine: case report. Clin Infect Dis. 1993;16(1):30-32.

174. Zhang J, Xi L, Lu C, Li X, Xie T, Zhang H, et al. Successful treatment for chromoblastomycosis caused by Fonsecae monophona: a report of three cases in Guangdong, China. Mycoses. 2009;52(2):176-181.

175. Anderson KL, Mitra S, Salouti R, Pham TA, Taylor HR. Fungal keratitis caused by Paecilomyces lilacinus associated with a retained intracorneal hair. Cornea. 2004;23(5):516-521.

176. Ford JG, Agee S, Greenhaw ST. Successful medical treatment of a case of Paecilomyces lilacinus keratitis. Cornea. 2008;27(9):1077-1079.

177. Ollague JM, de Zurita AM, Calero G. Paracoccidioidomycosis (South American blastomycosis) successfully treated with terbinafine: first case report. Br J Dermatol. 2000;143(1):188-191.

178. Gip L. Terbinafine for black piedra. Lancet. 1993;341(8853):1164.

179. Wong PK, Ching WT, Kwon-Chung KJ, Meyer RD. Disseminated Phialophora parasitica infection in humans: case report and review. Rev Infect Dis. 1989;11(5):770-775.

180. Coskun B, Saral Y, Akpolat N, Ataseven A, Cicek D. Sporotrichosis successfully treated with terbinafine and potassium iodide: case report and review of the literature. Mycopathologia. 2004;158(1):53-56.

181. Hull PR, Vismer HF. Treatment of cutaneous sporotrichosis with terbinafine. Br J Dermatol. 1992;126 Suppl 39:51-55.

182. Finlay AY. Global overview of Lamisil. Br J Dermatol. 1994; 130 Suppl 43:1-3.

183. Pollak R, Billstein SA. Safety of oral terbinafine for toenail onychomycosis. J Am Podiatr Med Assoc. 1997;87(12):565-570.

184. Villars V, Jones TC. Clinical efficacy and tolerability of terbinafine (Lamisil)--a new topical and systemic fungicidal drug for treatment of dermatomycoses. Clin Exp Dermatol. 1989;14(2):124-127.
185. De Backer M, De Vroey C, Lesaffre E, Scheys I, De Keyser P. Twelve weeks of continuous oral therapy for toenail onychomycosis caused by dermatophytes: a double-blind comparative trial of terbinafine $250 \mathrm{mg}$ /day versus itraconazole $200 \mathrm{mg}$ /day. J Am Acad Dermatol. 1998;38(5 Pt 3):S57-S63.

186. Drake LA, Shear NH, Arlette JP, Cloutier R, Danby FW, Elewski BE, et al. Oral terbinafine in the treatment of toenail onychomycosis: North American multicenter trial. J Am Acad Dermatol. 1997; 37(5 Pt 1):740-745.

187. Chang CH, Young-Xu Y, Kurth T, Orav JE, Chan AK. The safety of oral antifungal treatments for superficial dermatophytosis and onychomycosis: a meta-analysis. Am J Med. 2007;120(9):791-798.

188. Hall M, Monka C, Krupp P, O’Sullivan D. Safety of oral terbinafine: results of a postmarketing surveillance study in 25,884 patients. Arch Dermatol. 1997;133(10):1213-1219.

189. Agarwal K, Manas DM, Hudson M. Terbinafine and fulminant hepatic failure. N Engl J Med. 1999;340(16):1292-1293.

190. Fernandes NF, Geller SA, Fong TL. Terbinafine hepatotoxicity: case report and review of the literature. Am J Gastroenterol. 1998;93(3):459-460.

191. Brown PC. NDA 22-047; Lamisil ${ }^{\circledR}$ (terbinafine hydrochloride) Oral Granules. In: Administration FaD, editor; 2007.

192. Lowe G, Green C, Jennings P. Hepatitis associated with terbinafine treatment. BMJ. 1993;306(6872):248.

193. Paredes AH, Lewis JH. Terbinafine-induced acute autoimmune hepatitis in the setting of hepatitis B virus infection. Ann Pharmacother. 2007;41(5):880-884.

194. Committee ADRA. Terbinafine and blood dyscrasias. Australian Adverse Drug Reactions Bulletin. 2004;23:19.

195. Beltraminelli HS, Lerch M, Arnold A, Bircher AJ, Haeusermann P. Acute generalized exanthematous pustulosis induced by the antifungal terbinafine: case report and review of the literature. $\mathrm{Br} J$ Dermatol. 2005;152(4):780-783

196. Hivnor CM, Hudkins ML, Bonner B. Terbinafine-induced subacute cutaneous lupus erythematosus. Cutis. 2008;81(2):156-157.

197. Magro CM, Schaefer JT, Waldman J, Knight D, Seilstad K, Hearne D. Terbinafine-induced dermatomyositis: a case report and literature review of drug-induced dermatomyositis. J Cutan Pathol. 2008;35(1):74-81

198. Carstens J, Wendelboe P, Sogaard H, Thestrup-Pedersen K. Toxic epidermal necrolysis and erythema multiforme following therapy with terbinafine. Acta Derm Venereol. 1994;74(5):391-392.

199. Gupta AK, Porges AJ. Hypersensitivity syndrome reaction to oral terbinafine. Australas J Dermatol. 1998;39(3):171-172.

200. Kovacs MJ, Alshammari S, Guenther L, Bourcier M. Neutropenia and pancytopenia associated with oral terbinafine. J Am Acad Dermatol. 1994;31(5 Pt 1):806.

201. Rzany B, Mockenhaupt M, Gehring W, Schopf E. StevensJohnson syndrome after terbinafine therapy. J Am Acad Dermatol. 1994;30(3):509.

202. Todd P, Halpern S, Munro DD. Oral terbinafine and erythema multiforme. Clin Exp Dermatol. 1995;20(3):247-248.

203. Wach F, Stolz W, Hein R, Landthaler M. Severe erythema anulare centrifugum-like psoriatic drug eruption induced by terbinafine. Arch Dermatol. 1995;131(8):960-961.

204. Beutler M, Hartmann K, Kuhn M, Gartmann J. Taste disorders and terbinafine. BMJ. 1993;307(6895):26.

205. Bong JL, Lucke TW, Evans CD. Persistent impairment of taste resulting from terbinafine. Br J Dermatol. 1998;139(4):747-748.

206. Doty RL, Haxel BR. Objective assessment of terbinafine-induced taste loss. Laryngoscope. 2005;115(11):2035-2037.

207. Duxbury AJ, Oliver RJ, Pemberton MN. Persistent impairment of taste associated with terbinafine. Br Dent J. 2000;188(6):295-296.

208. Juhlin L. Loss of taste and terbinafine. Lancet. 1992;339(8807):1483.

209. Lemont H, Sabo M. Terbinafine-associated taste disturbance with normal taste threshold scores. J Am Podiatr Med Assoc. 2001;91(10): $540-541$. 
210. Ottervanger JP, Stricker BH. Loss of taste and terbinafine. Lancet. 1992;340(8821):728.

211. Stricker BH, Van Riemsdijk MM, Sturkenboom MC, Ottervanger JP. Taste loss to terbinafine: a case-control study of potential risk factors. Br J Clin Pharmacol. 1996;42(3):313-318.

212. Gupta AK, Gonder JR, Shear NH, Dilworth GR. The development of green vision in association with terbinafine therapy. Arch Dermatol. 1996;132(7):845-846.
213. Price T, Stallman J, Dretler RH. Anterior uveitis in a patient with AIDS who was treated with terbinafine for oral candidiasis: a potential drug-induced reaction. Clin Infect Dis. 1997;25(3):752-753.

214. Yulek F, Cagil N, Cakmak HB, Akcay EK, Simsek S, Kansu T. Bilateral anterior optic neuropathy associated with use of terbinafine. Clin Experiment Ophthalmol. 2008;36(5):488-489. 
